\title{
Rare Atmospheric River in Middle East
}

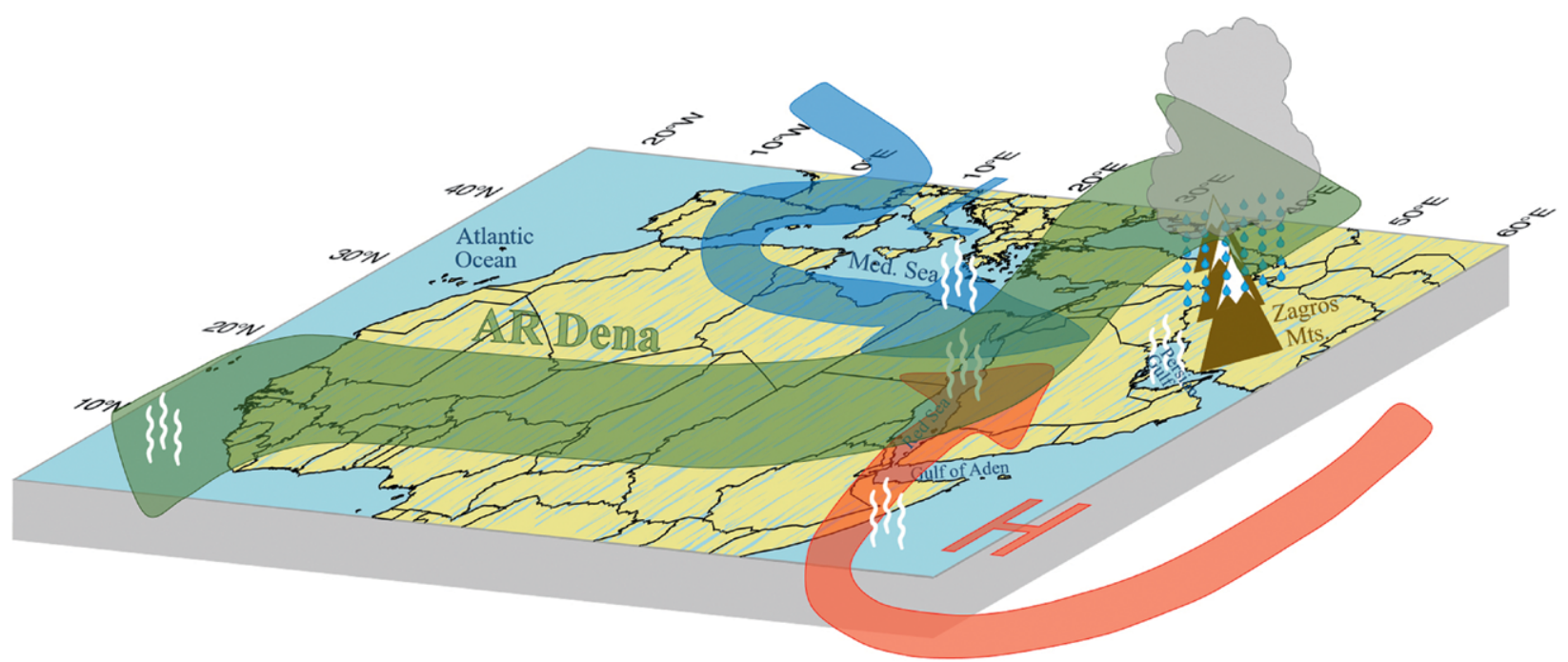

Adapted from the Map Room "Rare

Atmospheric River Caused Record Floods across the Middle East," by Amin Dezfuli (NASA Goddard Space Flight Center). Published online in BAMS, April 2020. For the full, citable article, see: https://doi .org/10.1175/BAMS-D-19-0247.1.

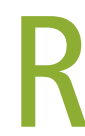

ecord rainfall in late March 2019 led to unprecedented flooding across several Middle Eastern countries and caused enormous damages and casualties, particularly in Iran. The intense rains have made the 2018/19 rainy season (October-March) the wettest in the past four decades, a sharp contrast with the prior year, which was the driest over the same period. Thus, this event is an example of rapid dry-to-wet transitions and intensification of extremes, potentially resulting from climate change.

An atmospheric river (AR), that originated from the tropical Atlantic Ocean was found responsible for the heavy precipitation that initiated the floods. To easily distinguish it from similar large-magnitude events over the region, here this AR is named "Dena," after the peak of the Zagros Mountains, which played a crucial role in precipitation formation. Moisture transport by AR Dena was equivalent to more than 150 times the aggregated flow of the 4 major rivers in the region: the Tigris, Euphrates, Karun, and Karkheh.

An AR of this magnitude can be rather rare for the Middle East. Specific synoptic weather conditions, including tropicalextratropical interactions of the atmospheric jets and anomalously warm sea surface temperatures (SSTs) in all surrounding basins, provided the necessary ingredients for formation of such a massive AR. Various features of AR Dena are schematically shown in F1. 

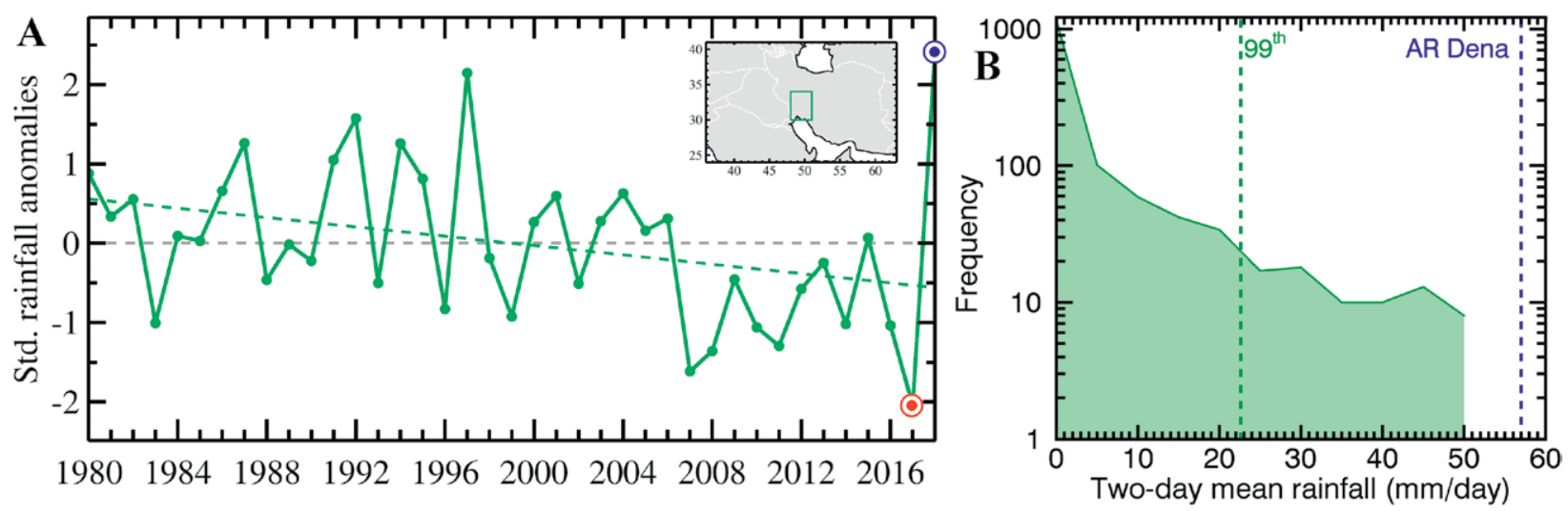

\section{Impacts of March 2019 floods}

Some hydroclimatic extremes around the world are caused by atmospheric rivers, defined as "long, narrow, and transient corridor[s] of strong horizontal water vapor transport" from tropical or extratropical moisture sources. ${ }^{1}$ While a large body of research has shown the impacts of ARs on weather-related disasters over various regions, including the western United States, little is known about their mechanisms and contribution to flooding in the Middle East. In fact, these two regions bear some geographical similarities, including their latitudinal extent, presence of a southeast-northwest-oriented mountain range overlooking a fertile plain, and the associated low-level barrier jets. Those mountain ranges are Zagros in the Middle East and Sierra Nevada in the western United States and their adjacent plains of Fertile Crescent and Central Valley, respectively.

In recent decades, increasing frequency and intensity of climatic extremes such as droughts and floods have imposed dramatic consequences for humans and ecosystems in the Middle East. The heavy precipitation during 24-25 March 2019 initiated widespread flooding across several countries, including Iran, which was hit hardest. The unprecedented floods affected 26 of 31 provinces in Iran, killing 76 people; causing an estimated $\$ 2.5$ billion (U.S. dollars) damage to infrastructure, homes, and agriculture; damaging one-third of the country's roads; destroying 700 bridges; and forcing mass emergency evacuations. The chance of flooding remained high several weeks after the event since major dams could not hold more water influx from spring snowmelt. Millions of people are still wrestling with the aftermath.
From Ralph et al. in the April 2018 BAMS.
$\Delta$

* F2. Rainfall variability and frequency. (a) Interannual variability of rainfall during the rainy season (October-March) over the region most affected by floods (inset box). Monthly data from Global Precipitation Climatology Project (GPCP), version 2.3, has been used to calculate seasonal rainfall totals for each year, 1980-2019. The total values have been then standardized by removing the mean and dividing by the standard deviation. The driest (2017/18) and wettest (2018/19) years are marked with red and blue circles, respectively. (b) Histogram of 2-day mean rainfall rate over the same region using GPCP daily 1DD V1.2 data available over the period 1996-2015. Note the logarithmic scale, the 99th percentile (green dashed line), and the 2-day mean daily average rainfall in AR Dena (blue dashed line).

The precipitation in March 2019 contributed significantly to the total seasonal rainfall. The 2-day mean rainfall [from Integrated Multisatellite Retrievals for GPM (IMERG) "late run"] was $57 \mathrm{~mm}$ day $^{-1}$ for 24-25 March. This exceeds the historical maximum of $\sim 50 \mathrm{~mm}$ day $^{-1}{ }^{\mathrm{F} 2 \mathrm{~b}}$. Some areas received $\sim 400 \mathrm{~mm}$ rainfall during this AR. The IMERG regional mean was consistent with some gauge-based records in the area.

The October-March 2018/19 rainy season averaged over southwestern Iran, the region most affected by the floods, was the wettest recorded during 1980-2019 F2a. By contrast, the prior year (2017/18) was the driest over the same period. The total seasonal rainfall in both years fell outside two standard deviations of the longterm mean, resulting in the largest year-to-year change in the past four decades-a compelling example of shifts from prolonged drought to frequent floods and potentially of "extremes becoming more extreme" in the changing climate. 

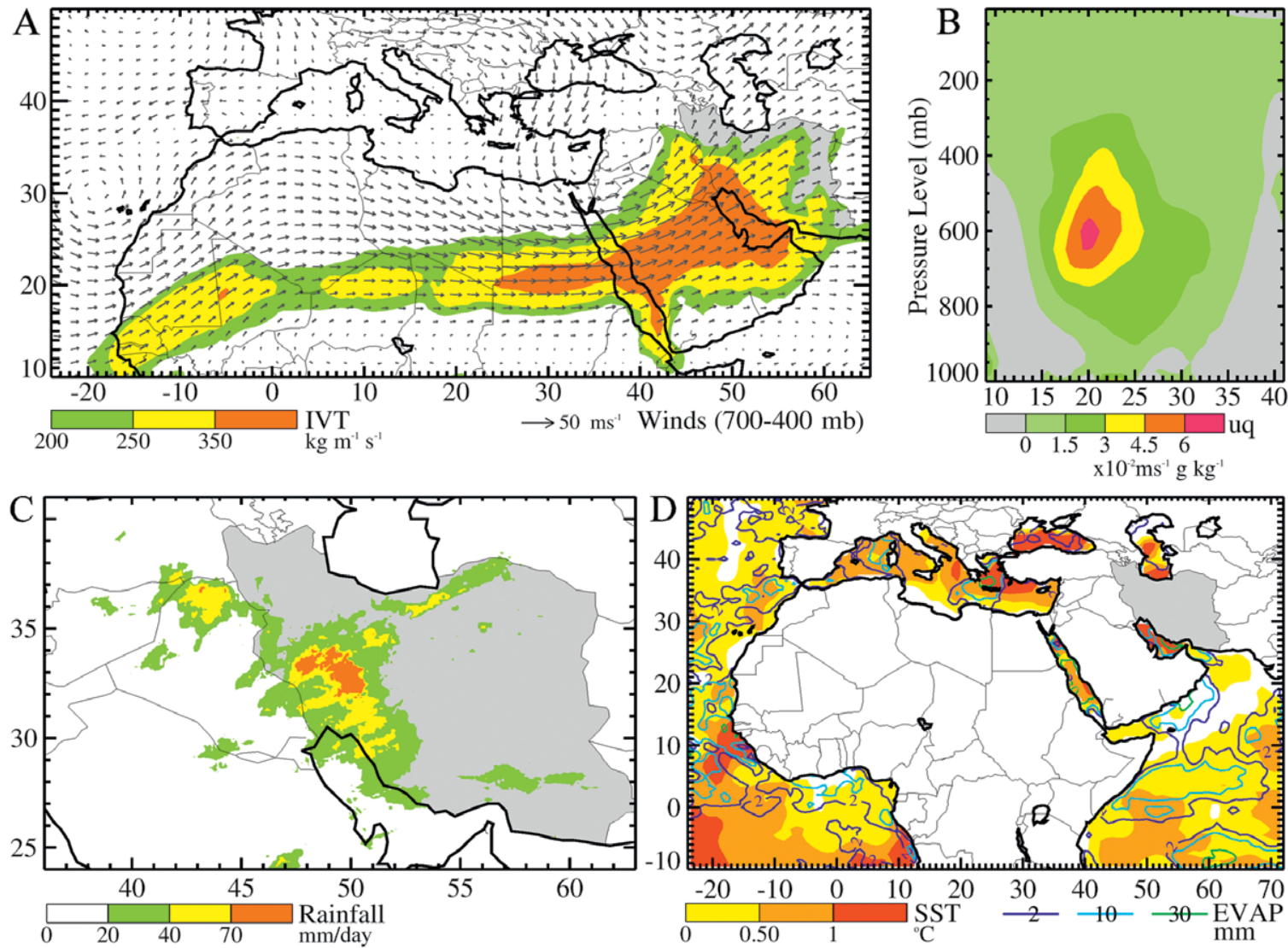

\section{What caused the heavy rains?}

Vertically integrated water vapor transport (IVT) is commonly used to identify ARs. Daily IVT data from NASA Modern-Era Retrospective Analysis for Research and Applications version 2 (MERRA-2) enable us to detect a strong, nearly 9,000-km-long AR propagating from the North Atlantic Ocean across the Middle East and North Africa F3a. To incorporate the aggregated effects of the features contributing to AR Dena, the 2-day mean IVT and the associated synoptic conditions have been analyzed. Typically, regions with IVT greater than $250 \mathrm{~kg} \mathrm{~m}^{-1} \mathrm{~s}^{-1}$ are considered to define ARs. In this study, a 200-kg m $\mathrm{m}^{-1} \mathrm{~s}^{-1}$ threshold has been used to account for less atmospheric moisture in the Middle East. AR Dena ranged between 200 and $350 \mathrm{~kg} \mathrm{~m}^{-1} \mathrm{~s}^{-1}$ as it passed southwesterly-westerly through the SahelSahara zone. Its IVT exceeded $350 \mathrm{~kg} \mathrm{~m}^{-1} \mathrm{~s}^{-1}$ over northeastern Africa and remained high as it propagated southwesterly toward Iran.

NASA satellite observations detected the maximum rainfall over the western half of Iran, where AR Dena hit the Zagros Mountains F3c. The moisture-laden air cools as it flows

\section{$\Delta$}

* F3. Atmospheric river Dena over the Middle East during 24-25 Mar 2019. (a) Two-day mean vertically integrated water vapor transport (IVT; shading) showing the spatial pattern of AR Dena and the associated horizontal winds (arrows) in the 700-400 $\mathrm{mb}$ layer. (b) Two-day mean vertical cross section of zonal moisture transport (uq), averaged over the longitudes $\left(15^{\circ} \mathrm{W}-52^{\circ} \mathrm{E}\right)$ of the AR. The NASA's MERRA-2 data are used in (a) and (b). (c) Two-day mean rainfall rate over the Middle East, using Integrated Multisatellite Retrievals for GPM (IMERG) "late run." (d) Sea surface temperature anomaly in March 2019, using NOAA Optimum Interpolation (OI) SST V2 (shading) and the associated evaporation anomaly (contour lines), using MERRA-2 data.

upslope, and the associated microphysical growth processes produce or strengthen the clouds. As a result of this uplift, the precipitation generation is enhanced mainly over the mountains and their windward side.

AR Dena approached the Zagros Mountains with an IVT of $350 \mathrm{~kg} \mathrm{~m}^{-1} \mathrm{~s}^{-1}$ across a 1,000-km width of the AR's core, as observed for example over the Arabian Peninsula F3a. This 


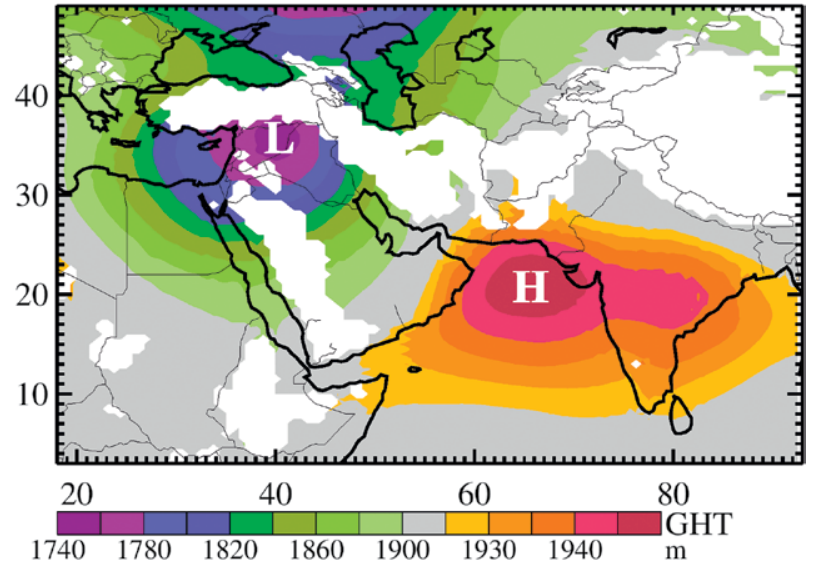

$\Delta$

* F4. Geopotential heights (GHT) in the lower troposphere (925-700 mb) during AR Dena (24-25 Mar 2019). Regions with surface pressure lower than $925 \mathbf{~ m b}$ are shaded in white. For better detection of the systems, contours are at 5- and 20-m intervals for high and low pressure areas, respectively.
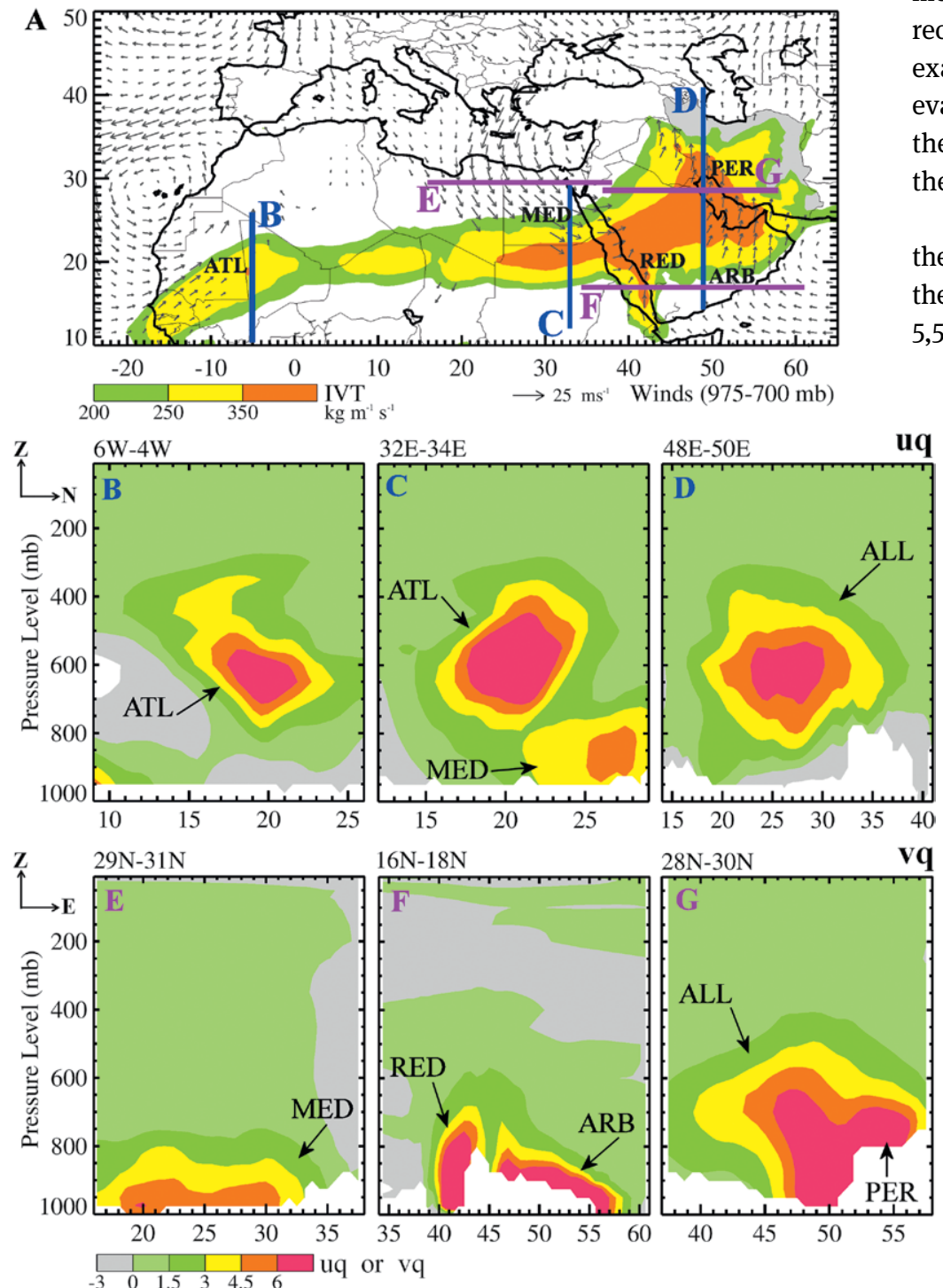

water transport is conservatively estimated at more than 150 times the discharge of the Arvand-Rud (aka Shatt al-Arab) River, the biggest river in Mesopotamia, which is formed by the confluence of four major regional riversthe Tigris $\left(815 \mathrm{~m}^{3} \mathrm{~s}^{-1}\right)$, Euphrates $\left(550 \mathrm{~m}^{3} \mathrm{~s}^{-1}\right)$, Karkheh $\left(185 \mathrm{~m}^{3} \mathrm{~s}^{-1}\right)$, and Karun $\left(775 \mathrm{~m}^{3} \mathrm{~s}^{-1}\right)$.

\section{Synoptic diagnostics of AR Dena}

The atmospheric and oceanic conditions in late March favored genesis of such a powerful AR over the Middle East. On its long journey from the equatorial Atlantic to Iran, AR Dena was likely fed by additional moisture from several other sources on the pathway of the low-level winds blowing toward the AR. All of the marine basins contributing to AR Dena were warmer than normal in March, and that suggests potential enhancement in their moisture supply F3d. Evaporation is more directly related to water vapor budget and is examined over the same domain as SST. The evaporation was anomalously positive over the contributing waters, particularly along the winds associated with the AR.

The zonal flux of water vapor, averaged over the entire extent of this AR, was maximum in the 700-500 mb layer (approximately 3,000$5,500 \mathrm{~m}$; F3b) and primarily determined by the

4* F5. Various water bodies contributing to the $A R$, such as the Atlantic Ocean (ATL), Mediterranean Sea (MED), Red Sea (RED), Arabian Sea (ARB), Persian Gulf (PER), and all the basins (ALL). (a) As in Fig. 3a, but for winds in the 975-700 mb layer. (b)-(d) Vertical cross section of zonal moisture transport $(u q)$, across the latitudes shown with blue lines in (a). (e)-(g) Vertical cross section of meridional moisture transport $(v q)$, across the longitudes shown with purple lines in (a). Unit of moisture transport is $10^{-2} \mathrm{~m} \mathrm{~s}^{-1} \mathrm{~g} \mathrm{~kg}^{-1}$. 
presence of a subtropical jet coming from the Atlantic Ocean. The jet then encountered a midlatitude weather system and merged with it approximately over the Red Sea. The low pressure component of this system was centered over the Fertile Crescent and its adjacent high pressure area was centered over the Arabian Sea F4.

This configuration facilitated moisture transport from the Arabian Sea, Gulf of Aden, and Red Sea toward the AR F5. The moisture contribution from the Mediterranean, the smallest amount of all basins, was also controlled by this system and confined to the lower troposphere. The Persian Gulf supplied moisture through the southerly winds associated with the high pressure region and the Zagros barrier jet (ZBJ), which is in turn induced by the midlatitude system. The ZBJ is similar to the Sierra barrier jet (SBJ), which has been shown to interact with landfalling ARs over California.

AR Dena can be characterized in the context of tropical-extratropical interactions, as it owes its existence to the combined effects of the aforementioned two features before its final landfall. This event is an example of moisture transport from remote sources initiating an AR, which is then maintained and even reinforced by additional horizontal aggregation of water vapor along the AR corridor, as shown for other regions.

\section{Future work}

This brief note provides some insight into the mechanisms influencing ARs over the Middle East by examining an individual extreme event. A comprehensive analysis of all ARs in the region is beyond the scope of this study and is a part of ongoing research. The plan is to extend the findings presented here by investigating the interannual variability of the ARs over the Middle East, using the 40-yr MERRA-2 records. That would enable a more robust understanding of the processes controlling the ARs. Leveraging such knowledge will enable use of the subseasonal-to-seasonal (S2S) predictions provided by the NASA Goddard Earth Observing System (GEOS) to offer potential improvement in seasonal predictions of the frequency of extreme precipitation events in the region, and thus help mitigate their adverse impacts. $\therefore$

This study was supported by Global Modeling and Assimilation Office (GMAO) National Climate Assessment (NCA) enabling tools funded by NASA.

\section{$\equiv$ METADATA}

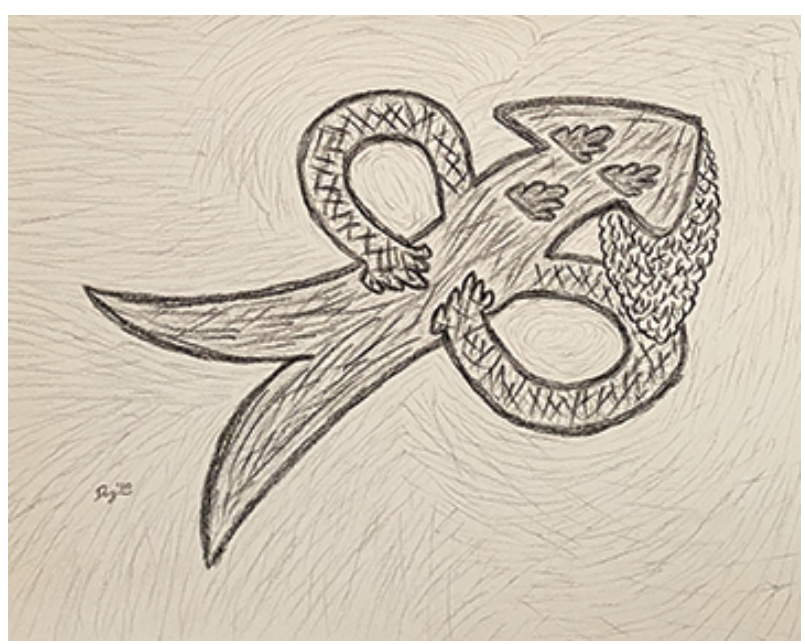

"Miss Dena, the Atmospheric River" - the author's artistic interpretation of F1, with legs for subtropical and midlatitude jets, clouds for eyes and mouth and precipitation as hair, and the low and high paired as two arms. More of Dr. Dezfuli's meteorological art appears in a future issue of BAMS.

BAMS: What is your take-away message in this short analysis?

Amin Dezfuli: The impacts of rain-producing atmospheric rivers (ARs) are not limited to the coastal regions. Such ARs can travel very long distances away from the oceans and affect remote arid and semi-arid regions like the Middle East.

BAMS: Why did you name the atmospheric river?

AD: It is an effort to "humanize" this phenomenon: in addition to being the peak that provide orographic lift, Dena is a female Persian name.

BAMS: How did you become interested in this storm?

AD: Study of climate and weather extreme events, particularly over vulnerable regions, is a major part of my research interests. Several colleagues at NASA's GMAO share similar interests. So, our frequent discussions on AR-related research got me initially interested in the topic. And, when in March 2019, I was following the news on record floods in Iran, I thought maybe an atmospheric river was responsible. A quick look at MERRA-2 data confirmed that assumption, and then I did several more diagnostics that helped completing this article.

BAMS: What surprised you most about this atmospheric river?

$\boldsymbol{A D}$ : It was interesting to see that an atmospheric river of this magnitude can maintain its moisture content, while propagating thousands of kilometers over deserts of North Africa and the Middle East, before its final landfall. 


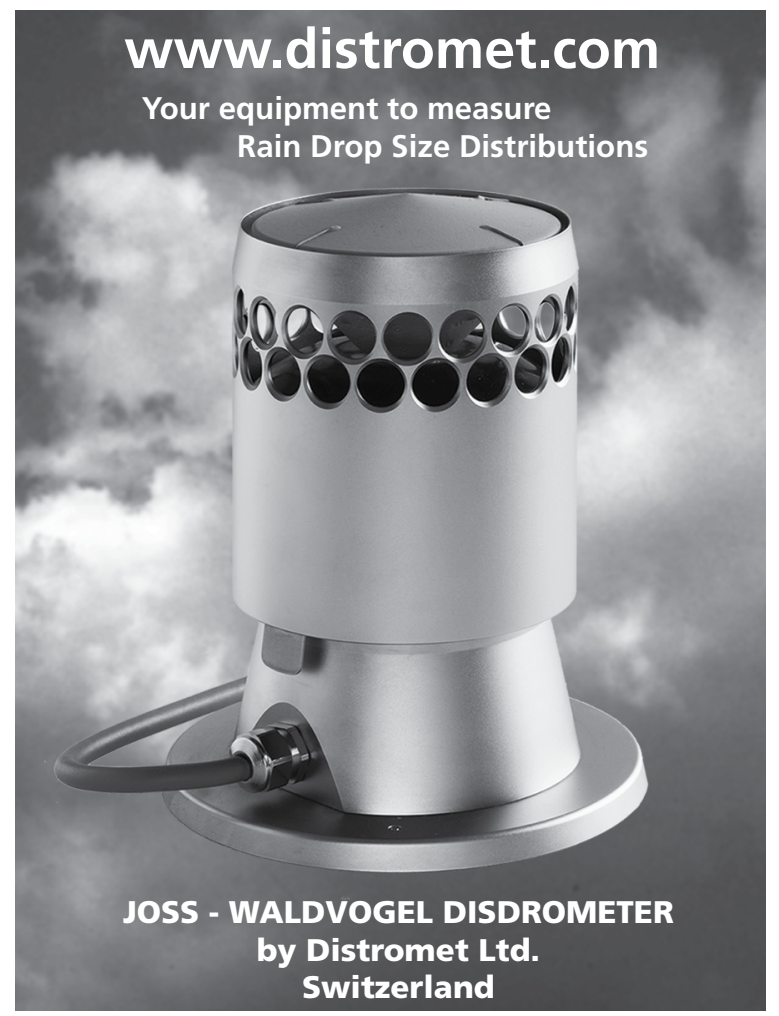

\section{FROM AMS BOOKS}

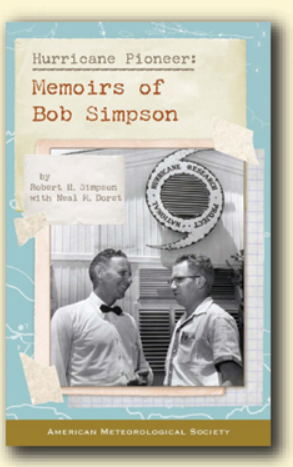

HURRICANE PIONEER: Memoirs of Bob Simpson BY ROBERT H. SIMPSON WITH NEAL DORST

In 1951, Bob Simpson rode a plane directly into the wall of a hurricane, just one of his many pioneering explorations. A meteorological icon, Bob was the first director of the National Hurricane Research Project and a director of the National Hurricane Center. He helped create the Saffir-Simpson Hurricane Scale; the public knows well his Categories $1-5$.

Bob's memoirs feature:

- His adventurous boyhood in Texas

- Being one of the first to fly directly into the path of a hurricane

- Traveling to burgeoning international centers of meteorologica study right as the science was developing

Proceeds from this book help support the American Meteorological Society's K. Vic Ooyama Scholarship Fund.

(C) 2015, PAPERBACK, 156 PAGES ISBN 13: 9781935704751

LIST \$25 AMS MEMBER PRICE \$20

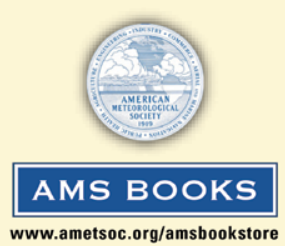

\section{NEW FROM AMS BOOKS!}

\section{The Ozone Layer:}

\section{From Discovery to Recovery}

\section{Guy P. Brasseur}

From the discovery of ozone in the eighteenth century, through the late twentieth century international agreements to protect humanity from the destruction of ozone in the stratosphere, Guy P. Brasseur traces the evolution of our scientific knowledge on air quality issues and stratospheric chemistry and dynamics.

This first complete study of ozone research demonstrates the key role fundamental research plays in solving global environmental, climate, and human health problems...and, more importantly, shows that the scientific method works.

Meanwhile, convincing decision makers of research results that do not correspond to their values, or to the interests of business groups, stands as the highest hurdle in using science to benefit society.

Guy P. Brasseur is a distinguished scholar and director of the Atmospheric Chemistry Observations and Modeling Laboratory at NCAR.

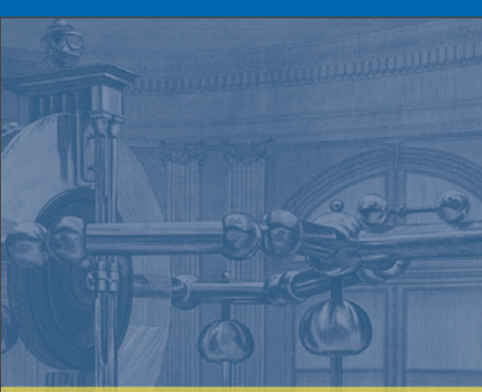

The Ozone Layer FROM DISCOVERY TO RECOVERY Guy P. Brasseur 